Published in final edited form as:

AIDS Behav. 2018 July ; 22(Suppl 1): 92-98. doi:10.1007/s10461-018-2172-8.

\title{
Factors associated with maternal-child transmission of HIV-1 in southeastern Brazil: a retrospective study:
}

\author{
Maternal-child transmission of HIV-1 in southeastern Brazil \\ Thiago Nascimento do Prado ${ }^{1,2}$, Deborah Bain Brickley ${ }^{3}$, Nancy K. Hills ${ }^{3}$, Eliana \\ Zandonade $^{2}$, Sandra Fagundes Moreira-Silva ${ }^{4}$, and Angélica Espinosa Miranda ${ }^{2,5}$ \\ ${ }^{1}$ Department of Nursing, Federal University of Espírito Santo, Espírito Santo, Brazil \\ ${ }^{2}$ Post-Graduate Program in Public Health, Federal University of Espírito Santo, Espírito Santo, \\ Brazil \\ ${ }^{3}$ Global Health Sciences, University of California, San Francisco, USA \\ ${ }^{4}$ Serviço de Infectologia, Hospital Infantil Nossa Senhora da Glória, Vitória, Espírito Santo, Brazil \\ ${ }^{5}$ Post-Graduate Program in Infectious Diseases, Federal University of Espírito Santo, Espírito \\ Santo, Brazil
}

\begin{abstract}
Mother-to-child transmission (MTCT) is the main mode of HIV-1 acquisition among young children worldwide. The goals of this study were to estimate the proportion of HIV MTCT and to identify factors associated with transmission. We reviewed data for HIV-infected pregnant women that had been reported to the National Information on Reportable Diseases System (SINAN) in Espírito Santo state, Brazil, between January 2007 and December 2012. HIV cases in children were followed until age 18 months. The proportion of women who transmitted HIV to their babies was $14 \%$ (95\% CI, $11 \%-17 \%)$. In a multivariate logistic regression model, pregnant women who had lower than primary school education $(\mathrm{OR}=2.74 ; 95 \% \mathrm{CI}, 1.31-5.71)$, had 2 or more pregnancies during the study period $(\mathrm{OR}=2.28 ; 95 \% \mathrm{CI}, 1.07-4.84)$, had emergency cesarean delivery $(\mathrm{OR}=4.32 ; 95 \% \mathrm{CI}, 1.57-11.9)$, and did not receive antiretroviral therapy during prenatal care (OR=2.41; 95\% CI, 1.09-5.31) had higher odds of HIV MTCT. Effort should be made to encourage health care workers and pregnant women to use services for the prevention of MTCT.
\end{abstract}

\section{RESUMEN}

La transmisión materno-infantil (TMI) es el principal modo de adquisición del VIH-1 entre los niños de todo el mundo. Los objetivos del estudio fueron estimar la tasa de TMI del VIH e

Corresponding author: Angélica Espinosa Miranda, Programa de Pós-graduação em Doenças Infecciosas, Universidade Federal do Espírito Santo. Av. Marechal Campos, 1468-Vitória-ES, Brazil. Phone: +55 27 33357210. Fax number: +55 27 3335-7504. espinosa@ndi.ufes.br.

Ethical approval

All procedures performed involving human participants were in accordance with the ethical standards of the institutional research committee and with the 1964 Helsinki declaration and its later amendments or comparable ethical standards. Informed consent was obtained from individual participants included in the study.

Conflict of Interest: The authors declare that they do not have conflict of interest. 
identificar los factores asociados. Se realizó una revisión de los datos de mujeres embarazadas infectadas por el VIH notificadas al Sistema Nacional de Información sobre Enfermedades Reportables (SINAN) en el estado de Espírito Santo/Brasil, entre enero de 2007 y diciembre de 2012. Los casos de VIH en niños fueron seguidos hasta 18 meses. La proporción de TMI fue del 14\% (IC95\%:10,9-17,0). En el modelo de regresión logística multivariable, las mujeres embarazadas que tenían menos que la educación primaria ( $\mathrm{OR}=2,74$; IC del 95\%: 1,31-5,71), que tuvieron dos o más embarazos durante el estudio del período (OR=2,28; $95 \%$ IC 1,07-4,84), que tuvieron el parto por cesárea de emergencia $(\mathrm{OR}=4,32$; IC95\%:1,57-11,9) y las mujeres embarazadas que no recibieron tratamiento antirretroviral durante la atención prenatal $(\mathrm{OR}=2,41$; IC95\%:1,09-5,31) tuvieron mayor probabilidad de TMI. Deberían realizarse esfuerzos para alentar a los trabajadores sanitarios ya las mujeres embarazadas a que utilicen los servicios de PTMI.

\section{Keywords}

infectious disease transmission; vertical transmission; HIV; pregnancy; retrospective studies

\section{Palabras claves}

transmisión de enfermedades infecciosas; transmisión vertical; VIH; embarazo; estudios retrospectivos

\section{INTRODUCTION}

Mother-to-child transmission (MTCT) is the dominant mode of HIV-1 acquisition among young children worldwide, resulting in at least 7000 new infections each day.[1] In Brazil, which is an upper-middle-income country, according to the World Bank, 92.8\% of AIDS cases in individuals younger than 13 years (during the years 1980 to 2015) were found to be due to MTCT (also called "vertical transmission"), and the most recent sentinel studies conducted in 2006 and 2010 found HIV prevalence to be $0.4 \%$ among pregnant women.[2,3]

The prevention of MTCT (PMTCT) is an urgent public health priority in low- and middleincome countries, because effective prophylaxis is currently available.[1] The Brazil Ministry of Health recommends HIV testing for all pregnant women, and compulsory reporting of HIV-positive pregnant women and of infants exposed to risk for HIV transmission. In addition, universal access to antiretroviral therapy (ART) is available through prenatal services and at maternity clinics,[4] breastfeeding is strongly discouraged, and formula is available to all mothers.

UNAIDS states that PMTCT programs should reduce the rate of HIV MTCT to $\mathbf{5} \%$ among breastfeeding populations and to $\mathcal{2} \%$ among nonbreastfeeding populations.[5] Despite the PMTCT initiatives, studies published in Brazil, which has a mostly nonbreastfeeding population, report a country prevalence of MTCT ranging from $2.8 \%$ to $18.9 \%$.[6-15] The MTCT rate for Latin American countries was 15.0\% (11.0\%-20.0\%) in 2010.[16] Some countries reported rates lower than $2.0 \%$, and others were close to the target; however, there are countries with higher MTCT rates, including Bolivia, Venezuela, and Guatemala.[16] 
To eliminate MTCT of HIV, it is important to identify and control factors that increase transmission. Several may be associated with MTCT, including both maternal and neonatal variables (eg, socioeconomic factors, high viral load, symptomatic illness, failure to take ART during pregnancy, vaginal delivery, low birth weight, and breastfeeding).[6-18] Many of these factors may be influencing the rate of MTCT in Brazil.[4]

Southeastern Brazil is the geographical region that reports the majority of MTCT cases in the country. Previous data from Vitoria (the capital of Espírito Santo state), reported an MTCT rate of 3.1\% in 2005[11] and 9.7\% in 2011.[19] Recent data showed an AIDS incidence of 3.2 per 100,000 per year among children younger than 5 years in Espírito Santo in 2014.[2] The goals of this study were to estimate the rate of HIV MTCT and to identify factors associated with MTCT in Espírito Santo.

\section{METHODS}

\section{Study design}

We conducted a secondary analysis of data that had been collected from HIV-infected pregnant women as part of the Brazil National Information on Reportable Diseases System (SINAN), which was developed in the early 1990s to collect and process data on disease reporting throughout the country. This surveillance system functions at the municipal, state, and federal levels to collect data and compile databases on diseases listed for compulsory reporting in Brazil, including HIV.[20] HIV-positive women who become pregnant, or pregnant women who test positive for HIV, are reported to SINAN and included in a database. For each case, an individual reporting form is completed by a health care worker at the time of HIV diagnosis (whether during prenatal care, at delivery, or postpartum) and recorded. Additional data are collected in an investigation report over the course of the gestational period. Both the reporting form and the investigation report are completed at the primary health care facility or hospital, and then sent to the municipality, where the data are transferred to the SINAN database. Files are transferred, via the internet or on compact disc sent by post, to the health district and subsequently to the state level. Data from all of the municipalities are consolidated and sent from the state to the federal level via the internet.

\section{Setting}

Espírito Santo state is one of 4 states in southeastern Brazil, with a population of 3.9 million. [21] Among the 26 states in Brazil, Espírito Santo ranks twelfth for HIV prevalence, both for adults and for children younger than 5 years.[2] Although the Brazilian guidelines for HIV state that all pregnant women should be tested for HIV, and even though Brazil offers free universal access to PMTCT programs, recent estimates are that only $62.3 \%$ of women who attend prenatal care have been tested for HIV.[2]

\section{Study population}

The study population included all HIV-positive pregnant women who had been reported to SINAN in Espírito Santo, Brazil, between January 1, 2007, and December 31, 2012. Only women who became pregnant during the specified time period were included, whether or not they had given birth to any children prior to 2007 . When deliveries occurred after the end of 
the study period, we followed the cases to verify the HIV status of the children. Because the majority of data we collected represent characteristics of the women who gave birth, we included only 1 birth per woman to ensure that all observations in the study were independent. Ideally, we would have included in the study the first child born to each woman. Because we lacked information on births prior to 2007, however, we could not assume that the first child born during our study period was indeed a woman's first-born child. To reduce the bias potentially caused by including children of different birth orders, we randomly selected 1 birth for each woman who had more than 1 child during the study period.

\section{Variables}

The data extracted from SINAN included the mother's age at time of delivery (categorized as 14-19 years, 20-25 years, 26-30 years, $31-35$ years, $\geq 36$ years), self-reported skin color (white, black, mixed, other colors), educational attainment (primary school or lower, higher than primary school), area of residence (rural, urban, peri-urban), type of delivery (elective cesarean, emergency cesarean, vaginal), number of pregnancies during the study period (1, 2), prenatal care received (no, yes), ART received during prenatal care (no, yes), ART received at delivery (no, yes), and ART prophylaxis in newborns ( $<=24$ hours after birth, $>$ 24 hours following birth, unknown). We also considered the timing of HIV diagnosis; because we were unable to obtain specific testing dates for women who had been tested prior to 2007, this variable was broadly categorized as having occurred before or during pregnancy, or at or after delivery (relative to a randomly chosen pregnancy, in the case of women who had more than 1 birth during the period).

Testing for HIV infection among pregnant women was conducted using dried blood spots with an enzyme immunoassay (EIA) (S\&S 903, Symbiosis Diagnostics Ltda, São Paulo, Brazil) or immunochromatographic rapid test (Rapid Check HIV $1 \&$ 2/NDI-UFES Vitoria, ES-Brazil). HIV-positive results were confirmed using Western blot test (HIV-Blot 2.21, Genelabs Diagnostics Pte Ltd, Singapore; or Biorad1, Cambridge Biotech Corporation, Worcester, Massachusetts, USA). The outcome variable for this study was HIV infection among children diagnosed according to Brazilian guidelines, which include "two detectable viral loads or two positive serological tests and a confirmatory indirect immunofluorescence assay or Western blot test by 18 months of age or one month after weaning, whichever came later."'[4]

\section{Statistical methods}

Characteristics potentially associated with vertically transmitted HIV infection were examined in univariate logistic regression models. Multivariate logistic regression analysis was also conducted, which included covariates associated with HIV vertical transmission at an alpha level of $P \leq 20$ in the univariate analysis. In our final multivariate model, an alpha level of $P \leq 05$ was used to determine statistical significance. While we acknowledge that we cannot make accurate estimates of incidence over this study period, given the way our sample was chosen, we nonetheless calculated a nonparametric trend test among the infants included in our cohort. All statistical tests were 2-sided. Data analysis was performed using Stata 13 (StataCorp, College Station, Texas, USA, 2013). 


\section{Ethical considerations}

The databases were acquired under the instructions for data release of the Secretariat of Health Surveillance and Health Care Department at the Brazil Ministry of Health, to safeguard confidentiality and ensure nondisclosure of individual identifying information. The Institutional Review Board of the Universidade Federal do Espírito Santo approved the study.

\section{RESULTS}

A total of 566 cases of pregnancy in HIV-positive women were reported between 2007 and 2012; of these, 15 stillbirths and 10 miscarriages were excluded from the study, resulting in 541 live births. Of these, 411 women had 1 child, 56 women had 2 children, and 3 women had 3 or more children. After randomly selecting 1 birth for each woman who had more than 1 child during the study period, the final study population included 470 women (Figure 1). The proportion of women who transmitted HIV to their babies was 14\% (95\% CI, 11\%$17 \%$ ). It was not possible to accurately calculate incidence of MTCT across the years covered by the study because some women had multiple births and we randomly selected 1 birth for each of these women. Therefore, while we present (for illustrative purposes only) a figure estimating incidence over time, neither the numerators nor the denominators used for these proportions takes into account all births or all infants born HIV positive. No trend was found across years among the infants included in our study $(\mathrm{P}=.54)$ (Figure 2).

The rate of MTCT was higher among pregnant women who had primary or lower education, compared with women who had more education (17.9\% vs 6.7\%, $P=.002)$; women who had 2 or more pregnancies during the study period, compared with women who had only 1 pregnancy ( $23.7 \%$ vs $12.7 \%, P<.025)$; and pregnant women who were diagnosed with HIV at delivery or in the postpartum period, compared with women who were diagnosed before or during the current pregnancy ( $24.4 \%$ vs $12.9 \%, P=.038$ ) (Table 1 ). In addition, MTCT was more frequent among pregnant women who did not receive ART during prenatal care, compared with women who did ( $21.2 \%$ vs $13.0 \%, P=.079)$, and among women who delivered by emergency cesarean (22.7\%), compared with women who delivered by elective cesarean $(12.3 \%)$ or vaginally $(12.5 \%)(P=.08)$. MTCT also differed by area of residence, with women who resided in peri-urban areas having a higher rate of MTCT (33.3\%) than women in urban (13.4\%) and rural (16.3\%) areas, although this difference was not statistically significant.

In a multivariate logistic regression model incorporating the significant covariates identified in univariate analysis, women who had a primary or lower level of education had greater odds of MTCT (adjusted odds ratio [aOR] $=2.74 ; 95 \% \mathrm{CI}, 1.31-5.71 ; P=.007$ ), compared with women who had higher than primary-level education (Table 2). Women who had 2 or more pregnancies during the study period $(\mathrm{aOR}=2.28 ; 95 \% \mathrm{CI}, 1.07-4.84 ; P=.03)$ had higher odds of MTCT, compared with women who had 1 pregnancy. Delivery by emergency cesarean was associated with increased odds of MTCT (aOR=4.32; 95\% CI, 1.57-11.90; $P=$. 005), compared with vaginal delivery, and pregnant women who did not receive ART during prenatal care had higher odds of MTCT $(\mathrm{aOR}=2.41 ; 95 \% \mathrm{CI}, 1.09-5.31 ; P=.03)$, compared with pregnant women who received ART during prenatal care. Although time of diagnosis 
was significantly associated with MTCT in univariate analysis, it was also highly correlated with prenatal ART; only $2 \%$ of women who were diagnosed with HIV at or after delivery had been on prenatal ART. Therefore, when both covariates were included in the multivariate model, time of diagnosis lost significance. We therefore excluded it from the final model, as it was likely a marker for receipt of prenatal ART (which would have lowered the rate of MTCT).

\section{DISCUSSION}

This study identified a high rate of MTCT of HIV (14\%) in Espírito Santo state, Brazil, from 2007 to 2012. The rate in our study is within the wide range described in previous Brazilian studies [6-19] and similar to the rates described for Bolivia, Venezuela, and Guatemala.[16] However, it is higher than the rates found in studies carried out in high-income countries where prevention measures have been implemented effectively.[22-24] According to a 2015 progress report by UNAIDS, the target for PMTCT programs is to reduce the rate of vertical transmission to $2 \%$ or lower among nonbreastfeeding populations.[5] Our data showed a higher rate of MTCT than recommended by UNAIDS, despite program investments in Brazil over the years and changes in the recommendations for PMTCT.[2]

Achieving the World Health Organization goal of zero vertical transmission of HIV is an important step toward achieving an AIDS-free generation. However, some low- and middleincome countries remain far from reaching this goal of protecting newborns from HIV infection.[1] Several factors may be associated with MTCT, including both maternal and neonatal variables.[6-17] In our study, an increased odds of MTCT was observed in women who had a primary or lower level of education, who had 2 or more pregnancies during the study period, who had an emergency cesarean delivery, and who had not received ART during prenatal care. It is unsurprising that lower education was associated with higher odds of MTCT in our study. In the face of more pressing concerns (eg, financial and food insecurity) and reduced access to services, women with lower levels of education may be less likely to prioritize health care or treatment. In addition, HIV infection often leads to stigmatization and discrimination, thereby increasing the vulnerability of these women.[25] A study conducted from 2000 to 2006 in neighborhoods in the capital of Espírito Santo state, which has a low rate of adequate sanitation that is also correlated to education level, identified a higher incidence of vertical HIV transmission.[19]

Current Brazilian guidelines call for HIV-infected women to deliver via scheduled cesarean when the maternal HIV viral load is $>1000$ copies $/ \mathrm{mL}$, in an effort to minimize transmission of HIV at delivery.[4] In our study, however, delivery by emergency cesarean was more than two times as likely to result in infection for the child, compared with vaginal delivery. The reason for this association is unclear. Emergency cesarean delivery is performed as an immediate intervention to improve maternal or fetal outcomes when there are indications such as fetal distress, prolapsed umbilical cord, maternal hemorrhage from previa or trauma, uterine rupture, or complete placental abruption.[26] In our study, an emergency cesarean could also have been performed because of inadequate prenatal care, late arrival at the hospital, or unavailability of places at reference maternity hospitals. 
The benefit of receiving ART during prenatal care to reduce HIV MTCT is well known.[5] Our study found that pregnant women who did not receive ART during prenatal care had higher odds of MTCT. It is important to highlight that some women received their diagnosis of HIV at delivery or immediately after delivery, and this can be a marker of poor access to prenatal health care. These data point to lost opportunities in conducting HIV prevention activities during prenatal care in Espírito Santo state. A study in 7 cities in Espírito Santo to assess the completeness of prenatal care information on patients' prenatal care cards showed that $35 \%$ of pregnant women had not received an HIV test result.[27]

Our study had several limitations. It is possible that women would be more likely to transmit HIV infection at their first delivery (and, if so, would be more apt to exhibit different behaviors during their subsequent pregnancies), yet we were unable to distinguish birth order of the infants included in the study. This would likely have the effect of underestimating transmission rates, however. The use of secondary databases such as SINAN may not reflect the total magnitude of MTCT cases, given the need for adequate completion of reporting forms by health professionals. Nevertheless, we believe that these findings can still help to identify health care strategies to improve public policies. Finally, missing data across variables reduced the total number of observations included in our multivariate analysis. However, the results were very consistent with those observed in univariate analysis, which generally included more observations. We therefore felt that the exclusion of variables in the multivariate model due to "missingness" was not likely to cause bias in our results.

Knowing the profile of pregnant women who are infected with HIV and the quality of care offered to them during pregnancy, at delivery, and postpartum is important for devising increasingly effective strategies to control MTCT, evaluate the quality of a health care system, and determine the vulnerability of women in that system. Health information systems can offer a basis for monitoring and evaluating services and conditions in municipalities and states, and thereby lead to improvements in health care organization, management, and strategies.

\section{Acknowledgments}

We wish to acknowledge support from the University of California, San Francisco's International Traineeships in AIDS Prevention Studies (ITAPS), U.S. NIMH, R25MH064712 and the Starr Foundation Scholarship Fund. In addition, we wish to acknowledge support from the Brazilian Ministry of Health, National Foundation of Health. Grant \# Termo de 323/2014.

\section{References}

1. Joint United Nations Programme on HIV/AIDS (UNAIDS)Global HIV/AIDS Response: Epidemic update and health sector progress towards universal access, Progress Report 2011 UNAIDS; 2011

2. Brasil. Ministério da SaúdeSecretaria de Vigilância em Saúde. Boletim Epidemiológico - Aids e DST. Ano V - n 1 Brasília: Ministério da Saúde; 2016 http://www.aids.gov.br/pt-br/pub/2016/ boletim-epidemiologico-de-aids-2016 [Accessed [20/09/2017]]

3. Szwarcwald CL, Barbosa Junior A, Souza-Junior PR, et al. HIV testing during pregnancy: use of secondary data to estimate 2006 test coverage and prevalence in Brazil. Braz J Infect Dis. 2008; 2:167-172. 
4. Brasil. Ministério da SaúdeProtocolo Clínico e Diretrizes Terapêuticas para Prevenção da Transmissão Vertical de HIV, Sífilis e Hepatites Virais Brasília: Ministério da Saúde; 2016 Secretaria de Vigilância em Saúde. Programa Nacional de DST e Aids. http://www.aids.gov.br/ptbr/pub/2015/protocolo-clinico-e-diretrizes-terapeuticas-para-prevencao-da-transmissao-vertical-dehiv [Accessed [18/10/2017]]

5. Joint United Nations Programme on HIV/AIDS (UNAIDS). 2015 Progress Report on The Global Plan towards the elimination of new HIV infections among children and keeping their mothers alive. 2015

6. Tess BH, Rodrigues LC, Newell ML, Dunn DT, Lago TD. Infant feeding and risk of mother-to-child transmission of HIV-1 in São Paulo State, Brazil. São Paulo Collaborative Study for Vertical Transmission of HIV-1. J Acquir Immune Defic Syndr Hum Retrovirol. 1998; 19:189-194. [PubMed: 9768630]

7. Nogueira SA, Abreu T, Oliveira R, et al. Successful prevention of HIV transmission from mother to infant in Brazil using a multidisciplinary team approach. Braz J Infect Dis. 2001; 5:78-86. [PubMed: 11493413]

8. João EC, Cruz ML, Menezes JA, et al. Vertical transmission of HIV in Rio de Janeiro, Brazil. AIDS. 2003; 17:1853-1855. [PubMed: 12891073]

9. Mussi-Pinhata MM, Kato CM, Duarte G, Paschoini MC, Bettiol H, Quintana SM. Factors associated with vertical HIV transmission during two different time periods: the impact of zidovudine use on clinical practice at a Brazilian reference center. Int J STD AIDS. 2003; 14:818-825. [PubMed: 14678590]

10. Fernandes RC, Araújo LC, Medina-Acosta E. Prevention of vertical HIV transmission in Campos dos Goytacazes, Rio de Janeiro, Brazil. Cad Saúde Pública. 2005; 21:1153-1159. [PubMed: 16021252]

11. Miranda AE, Soares RA, Prado BC, Monteiro RB, Figueiredo NC. Mother to child transmission of HIV in Vitória, Brazil: factors associated with lack of HIV prevention. AIDS Care. 2005; 17:721728. [PubMed: 16036258]

12. Kakehasi FM, Pinto JA, Romanelli RM, et al. Determinants and trends in perinatal human immunodeficiency vírus type 1 (HIV-1) transmission in the metropolitan area of Belo Horizonte, Brazil: 1998 - 2005. Mem Inst Oswaldo Cruz. 2008; 103:351-357. [PubMed: 18660989]

13. Dal Fabbro MM, Cunha RV, Paniago AM, Lindenberg AS, Freitas GM, Nogueira SA. Prospective study on the prevention of vertical transmission of HIV in Campo Grande, Mato Grosso do Sul, Brazil, from 1996 to 2001. Braz J Infect Dis. 2005; 9:20-27. [PubMed: 15947843]

14. Torres SR, Luz AMH. HIV + pregnant woman and exposed children: epidemiological study on compulsory notification. Rev Gauch Enferm. 2007; 28:505-511.

15. de Lemos LM, Lippi J, Rutherford GW, et al. Maternal risk factors for HIV infection in infants in northeastern Brazil. Int J Infect Dis. 2013; 17(10):e913-e918. [PubMed: 23791426]

16. Pan American Health Organization (PAHO)Elimination of mother-to-child transmission of HIV and syphilis in the Americas Washington, D.C: PAHO; 2017 Update 2016. http://iris.paho.org/ xmlui/bitstream/handle/123456789/34072/9789275119556-eng.pdf?sequence=4\&isAllowed=y [Accessed [04/12/2017]]

17. Gulland A. Cuba is first country to eliminate mother to child HIV transmission. BMJ. 2015; 351:h3607. [PubMed: 26138937]

18. Menezes Succi RC. Mother-to-child transmission of HIV in Brazil during the years 2000 and 2001: results of a multi-centric study. Cad Saúde Pública. 2007; 23(suppl 3):379-389. (3).

19. Vieira ACBC, Miranda AE, Vargas PRM, Maciel ELN. Prevalência de HIV em gestantes e transmissão vertical segundo perfil socioeconômico, Vitória, ES. Rev Saúde Pública. 2011; 45(4): 644-651. [PubMed: 21739080]

20. Cerqueira ACB, Sales CMM, Lima R, et al. Completude do sistema de informação de agravos de notificação compulsória de gestante HIV positivo entre 2001 e 2006, no Espírito Santo, Brasil. UFES Rev Odont. 2008; 10(1):33-37.

21. Instituto Brasileiro de Geografia e EstatísticaSenso 2010. Espirito Santo Brazil: Instituto Brasileiro de Geografia e Estatística; 2010 http://cod.ibge.gov.br/96J [Accessed May 12, 2016] 
22. Forbes JC, Alimenti AM, Singer J, et al. A national review of vertical HIV transmission. AIDS. 2012; 26(6):757-763. [PubMed: 22210635]

23. Duong T, Ades AE, Gibb DM, Tookey PA, Masters J. Vertical transmission rates for HIV in the British Isles: estimates based on surveillance data. BMJ. 1999; 319:1227-1229. [PubMed: 10550082]

24. Lindegren M, Byers RH, Thomas $\mathrm{P}$, et al. Trends in perinatal transmission of HIV/AIDS in the United States. JAMA. 1999; 282:531-538. [PubMed: 10450714]

25. Lopes F, Buchalla M, Ayres JRCM. Mulheres negras e não-negras e vulnerabilidade ao HIV/Aids no estado de São Paulo, Brasil. Rev Saúde Pública. 2007; 41(suppl 2):39-46. [PubMed: 18094785]

26. Isono WL, Nagamatsu T, Uemura Y, et al. Prediction model for the incidence of emergent cesarean section during induction of labor specialized in nulliparous low-risk women. J Obstet Gynaecol Res. 2011; 37(12):1784-1791. [PubMed: 21793999]

27. Santos Neto ET, Oliveira AE, Zandonade E, Gama SGN, Leal MC. O que os cartões de pré-natal das gestantes revelam sobre a assistência nos serviços do SUS da Região Metropolitana da Grande Vitória, Espírito Santo, Brasil? Cad Saúde Pública. 2012; 28(9):1650-1662. [PubMed: 23033181] 


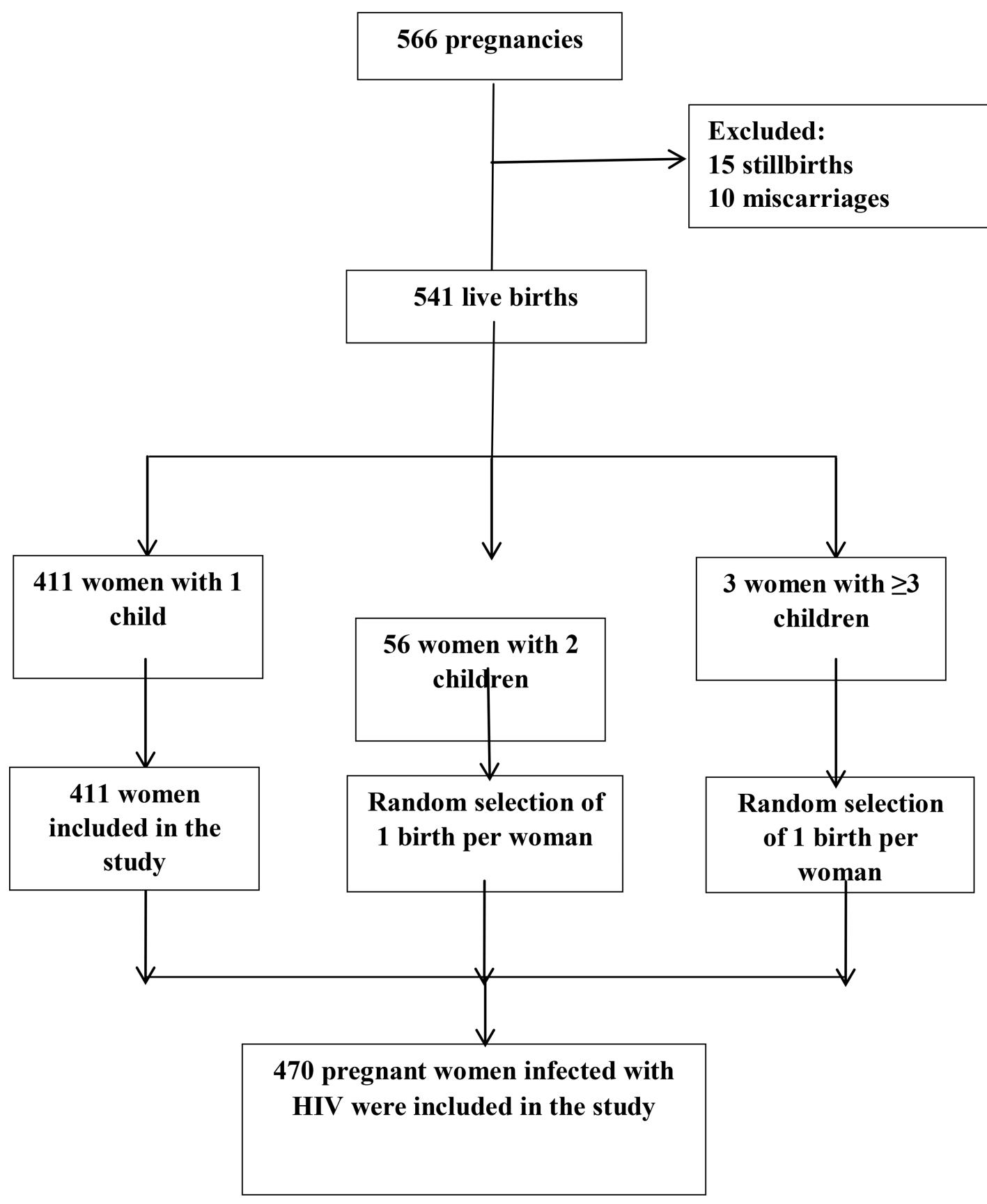

Figure 1. Study flow diagram

Model of the random selection to remove duplicates of pregnant women who had 2 or more pregnancies during the study period. 


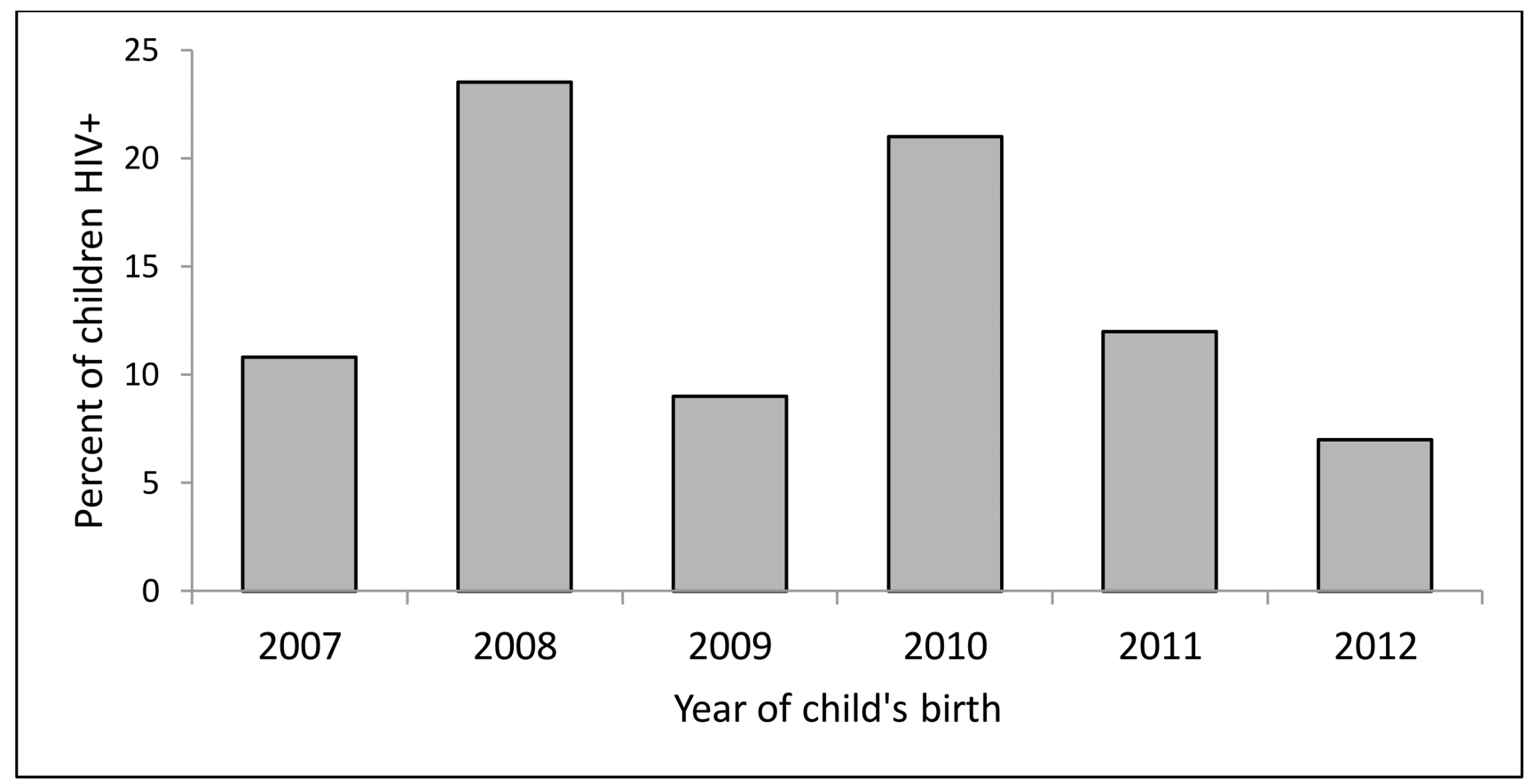

Figure 2.

Incidence estimate over time. (Neither the numerators nor the denominators used for these proportions takes into account all births or all infants born HIV positive.) 




AIDS Behav. Author manuscript; available in PMC 2019 July 01. 

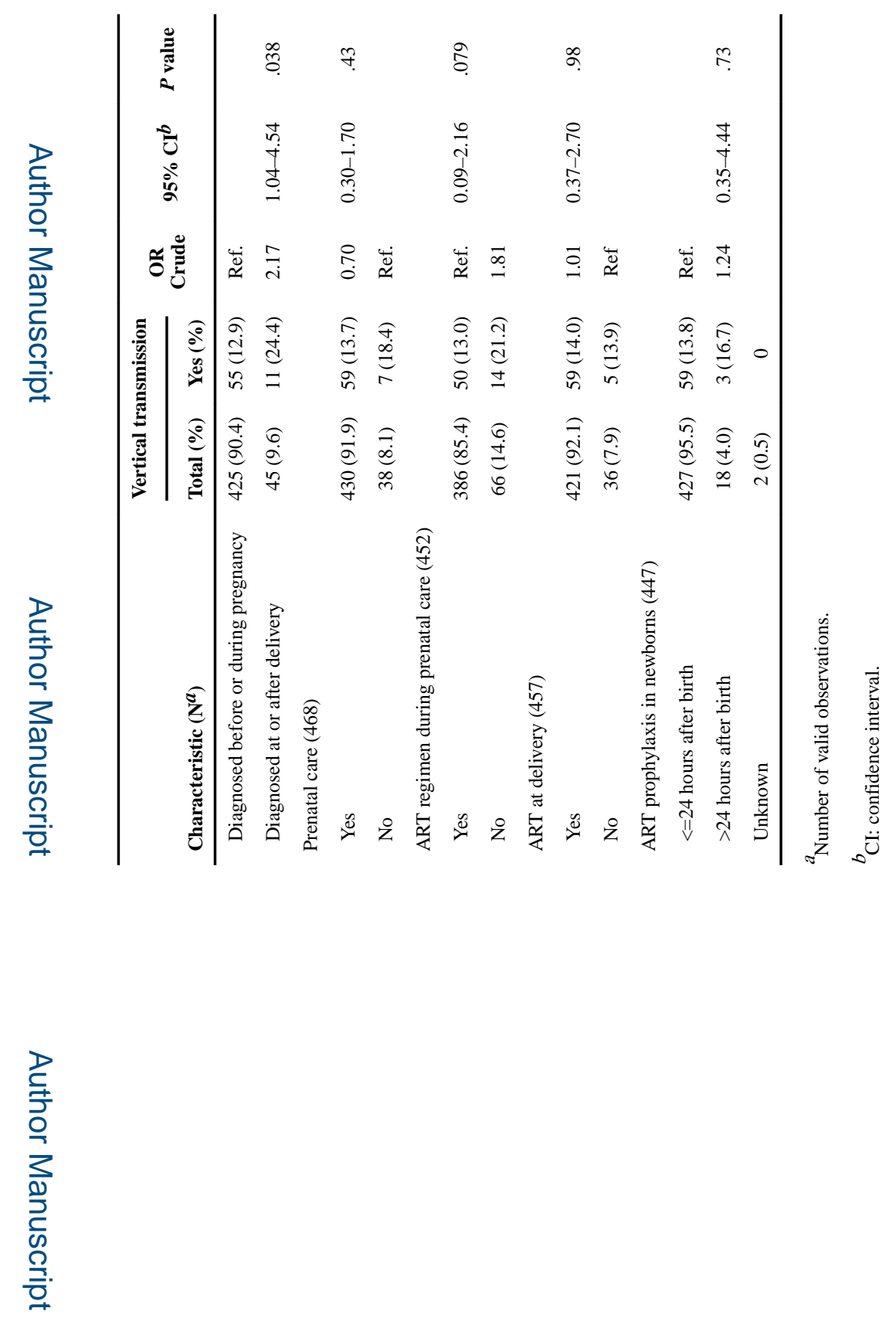

로을

AIDS Behav. Author manuscript; available in PMC 2019 July 01. 


\section{Table 2}

Multivariate logistic regression of sociodemographic and clinical covariates associated with vertical transmission of HIV in Espírito Santo state, Brazil, 2007-2012.

\begin{tabular}{|c|c|c|c|}
\hline Characteristic & Adjusted $\mathrm{OR}^{a}$ & $95 \% \mathrm{CI}^{b}$ & $P$ value \\
\hline \multicolumn{4}{|l|}{ Education level } \\
\hline > Primary school & Ref. & & \\
\hline$\leq$ Primary school & 2.74 & $1.31-5.71$ & .007 \\
\hline \multicolumn{4}{|l|}{ Type of delivery } \\
\hline Vaginal & Ref. & & \\
\hline Elective cesarean & 1.93 & $0.79-4.70$ & .15 \\
\hline Emergency cesarean & 4.32 & $1.57-11.90$ & .005 \\
\hline \multicolumn{4}{|c|}{ Pregnancies during study period } \\
\hline 1 & Ref. & & \\
\hline 2 or more & 2.28 & $1.07-4.84$ & .03 \\
\hline \multicolumn{4}{|c|}{ ART received during prenatal care } \\
\hline Yes & Ref. & & \\
\hline No & 2.41 & $1.09-5.31$ & .03 \\
\hline
\end{tabular}

